\title{
The relationship between dimensions of intellectual capital and knowledge creation: Case Study of the headquarters of national gas corporation of Iran
}

\author{
Mehdi Sharafi $^{\mathrm{a}}$, Yousof Mohammadi moghadam ${ }^{\mathrm{b}}$ and Tavakol Sharafi $\mathrm{i}^{\mathrm{*}}$
}

${ }^{a}$ Department of Management \& Accounting, Payame Noor University, Lorestan, Iran

${ }^{b}$ Department of Governmental Management, Police University of Iran, Tehran, Iran

${ }^{c}$ Department of Management \& Accounting, Allameh Tabataba'i University, Tehran, Iran

\begin{tabular}{l}
\hline A R T I C L E I N F O \\
\hline Article history: \\
Received July 19, 2011 \\
Received in Revised form \\
September, 6, 2011 \\
Accepted 11 September 2011 \\
Available online \\
17 September 2011 \\
\hline Keywords: \\
Intellectual capital \\
Structural capital \\
Relational capital \\
Human capital \\
Knowledge creation
\end{tabular}

\author{
A B S T R A C T
}

Intellectual capital is the main property of any organization in knowledge-based economics. Knowledge is the fundamental principle of intellectual capital. Hence, it is the core of organizational capabilities. The aim of this study is to survey the relationship between dimensions of intellectual capital and knowledge creation in the headquarters of National Gas Corporation of Iran in the year 2010. The research method is descriptive - survey and follows practical objective. The research population consists of the formal staffs of the Corporation (managers, senior staff and other staff). We selected 261 people from the population randomly. We also used a reliable and valid questionnaire to gather data .

We also used informative factor analysis to examine goodness of the model and we used SEM by Lisrel to confirm or reject the hypothesis in this study. The results show that all dimensions of intellectual capital have a significant impact on dimensions of knowledge creation, except for the effects of structural capital on knowledge combination as well as relational capital on knowledge internalization.

\section{Introduction}

Knowledge is one of the necessary tools for corporate competition. Guthrie (2001) recommended that many firms cannot gain benefits solely based on tangible assets, and they mostly use intangible information and knowledge creation as their major resources for success. The concept of assessing enterprise value using tangible assets has gradually changed into intangible knowledge development and integration ability. Intangible knowledge advancement and integration capability is a set of management skills, which could develop and restructure human capital, structural capital, and customer capital of an organization. Using an integrated of knowledge management many companies have been able to create core competitiveness. Wu (2002) indicated that for knowledge-type firms, creation, accumulation, sharing, and integration of knowledge are the keys success for the creation of corporate value and sustainable operations. Creation, management, measurement, and evaluation of

* Corresponding author. Tel: +0989395886550

E-mail addresses: t.sharafi1986@gmail.com (T. Sharafi) 
core intellectual capital (IC) are important indicators of the value of corporate competitiveness in the future.

Many traditional KM literatures addressing IC have concentrated on the correlation between IC and organizational performances (Ho, 2009). There are very few researches on the relationship between knowledge creation and IC, and even few investigations on the relationship between intellectual capital dimensions and knowledge creation dimensions.

According to Rezgui et al. (2007) there is a close relationship between the accumulation of IC and knowledge creation, IC is generated via systematic integration of knowledge, and it is understood for their diversity and abstractness. From the selection of the management team, the development of professional skills of employees, nurturing of the creativity of employees, accumulation of innovative and creative capabilities, screening of customer groups, and management of customers' loyalty, to develop and manage strategic partners, all sources of enterprise value through the creation and management of corporate knowledge.

This paper examines the empirical studies on knowledge creation and IC. The major purpose is to explore the relationship between Intellectual Capital dimensions (human capital, structural capital, and relational capital) and knowledge creation dimensions (Socialization, Externalization, Combination, Internalization), through the construction of the correlation patterns between these two elements. This paper hopes to provide practical suggestions for the reference of the management of Gas National Corporation Headquarter.

\section{Literature review}

\subsection{Definition of intellectual capital}

IC was first proposed by Galbraith (1969), as a form of knowledge, intellect, and brainpower activity, which uses knowledge to create value. Any firm could create advantages with this kind of capital and it plays important role on the success of firms (Joia, 2000). Stewart (1997) reported that IC is an aggregation of all kinds of knowledge and competences of employees, which could bring about competitive advantages for firms. Any intellectual materials, which could generate wealth, such as knowledge, information, etc. can be the most valuable assets and most advantageous tools in competition. Phusavat and Kanchana (2007) recommended that any knowledge capabilities stemming from manpower, or affiliated parties can be classified as IC, providing it can store and convert knowledge for value creation in the future or translate implicit knowledge of employees into explicit knowledge for organizational structure. Schiuma and Lerro (2008) believe that human, relational, structural, and social capital as four main knowledge-based categories building the knowledge-based capital of a region. Walsh et al. (2008) reported that the investments of companies in the enhancement of human capital, structural capital, and relational capital would increase their organizational assets.

Dzinkowski (2000) explained IC as the total inventor of assets or knowledge-based resources owned by an organization. Therefore, IC can be considered as the intellectual properties transferred by knowledge. Al-Ali (2003) explained that IC is the knowledge and experience as well as the knowledge resources stored in the database, systems, workflows, cultures, and management philosophy within an organization. Bontis (2004) claimed that IC can be considered a stock of knowledge at a given time. Schiuma and Lerro (2008) argued that the most important activities in the management of IC are the improvement of organizational flows and management techniques to create knowledge assets.

There are other studies, which describe IC as intangible assets within an organization. According to Mayo (2001) IC is the synonym of knowledge, information, intellectual properties, experience, and other intangible assets. Mason (2006) explained that IC is an intangible asset and can be defined as 
"the aggregation of the employees and internal structure of a company". IC includes three types: delivery and management system of company information; the abilities of employers and employees, and when the employees leave, the company loses the IC; and the relationship connectors with external organizations, such as relationship with customers, goodwill, and reputation.

Other scholars define IC with different perspectives. Rastogi (2000) stated that IC is the ability owned by an organization as a whole to constantly face existing and potential challenges, and respond in a creative and effective manner. McElroy (2002)suggested that IC should include social and innovative capital that enhances the internal value of companies with mutual trust, mutual benefits, shared values, networks, and norms. Cuganesan (2005) investigates the inter-relationships between different components of IC and value creation in an Australian financial services firm. The actual inter-relationships between different IC elements and value creation were found to be pluralistic and temporally contingent. Petty et al. (2008) argued that IC is the link between personal knowledge within group of an organization, and it can serve as a basis for decision making.

\subsection{Intellectual capital dimensions}

Although for a long time it has been recognized that economic wealth comes from knowledge assets - i.e. intellectual capital - and its useful application, the emphasis on it is relatively new. Managing the intellectual capital of the firm has become one of the main tasks on the executive agenda. Nevertheless, this work is especially difficult because of the problems involved in its identification, measurement and strategic assessment. In this situation, the models of intellectual capital become highly relevant, because they not only allow us to understand the nature of these assets, but also to carry out their measurement.

Several contributions have provided different frameworks for classifying the different components of intellectual capital, as well as for establishing series of indicators for intellectual capital measurement. Thus, according to the most theoretical proposals, in a first step, three main components can be found:

1. Human capital,

2. Structural capital and

3. Customer or relational capital.

Without a doubt, we need a detailed classification to access a better understanding. Brooking (1996) highlighted the differences between intellectual property assets and infrastructure assets and gave a broader concept of market assets, which include customer assets (Petty et al., 2008). Other intellectual capital proposals include five components:

1. Human capital -makes reference to the tacit or explicit knowledge which people possess, as well as their ability to generate it, which is useful for the mission of the organization and includes values and attitudes, aptitudes and know-how;

2. Technological capital - refers to the combination of knowledge directly linked to the development of the activities and functions of the technical system of the organization, responsible for obtaining products and services;

3. Organizational capital - the combination of explicit and implicit, formal and informal knowledge which in an effective and efficient way to structure and develop the organizational activity of the firm, that includes culture (implicit and informal knowledge), structure (explicit and formal knowledge) and organizational learning (implicit and explicit, formal and informal renewal knowledge processes);

4. Business capital - refers to the value to the organization of the relationships where it maintains with the main agents connected with its basic business processes (customers, suppliers, allies, etc.) and 
5. Social capital - the value to the organization of the relationships, where it maintains with other social agents and its surroundings (Chong \& Lin, 2008)

In this research, we consider the most popular components of intellectual capital in the literature. These components include: human capital, structural capital and relational capital. In the next section, we will explain each of these.

\subsubsection{Human capital}

Human capital provides the individual knowledge embedded in the mind of the employees. Human capital plays an important role as the foundational source of innovation, strategic renewal of a particular firm and the firm can understand and create value in the knowledge-based economy. Human capital can be defined as a combination of employee's competence, attitude and creativity (Table 1). Employees' competence is the hard part of IC. It includes employee's knowledge, skills, talents, and knack, of which knowledge and skill are uppermost. Knowledge, which consists of technical knowledge and academic knowledge, is obtained mainly through school education and is thus theoretical. Skills, the employee's capability of accomplishing practical assignments, are obtained primarily through practice, especially the tacit skills that cannot be literally expressed, even though it can also be developed through school education. Employees' attitude is the soft part of IC, including their motivation for work and satisfaction from work. It is regarded as the prerequisite for employees to give full play to their competence. Employees' creativity enables them to use their knowledge elastically and to make innovations continuously. It is therefore one of the key factors in developing the IC of an enterprise (Chen et al., 2004).

Table 1

The indices of human capital (Chen et al., 2004)

Strategic leadership of the management

Qualities of the employees

Learning ability of the employees

Efficiency of employee training

Employees' competence The employees' ability to participate in policy

making and management

Training of key technical and managerial employees

Identification with corporate values

Employees' attitude Satisfaction degree

Employees' turnover rate

Employees' average serviceable life

Employees' creativity Employee's creative ability

Income on employees' original ideas

\subsubsection{Structural capital}

Structural capital is associated with the structure of an enterprise and the business routines. An enterprise with strong structural capital can create good conditions to utilize human capital and create the opportunity for human capital to understand its fullest potential, and boosts its innovation capital and customer capital. In detail, structural capital can be classified into company culture, organizational structure, organizational learning, operational process, and information system (Table 2). A company's culture is the values, faith and behavior criteria approved and shared by all the staff. Values are what a company regards as the most important to its business, employees and customers. Faith is associated with an employee's attitude towards him/herself, his/her company and customers. Meanwhile behavioral criteria are the unwritten rules emphasizing such matters as employees' appearance and cooperation with one another. Company culture under the guidance of a attractive managing philosophy is a valuable asset. 
Organizational structure is the power and responsibility structure formed in the managing process. This power and responsibility structure can find expression in the policy-making structure, the leading structure, the controlling structure and the information structure. Organizational competence is the result of the perennial learning and accumulating, and it is becoming one of the most important core competences of a company. It is affirmed that in the twenty-first century the only way for a successful company to maintain its competitive excellence is to be quicker in learning than its competitors (Chen et al., 2004, p. 204).

The operational process, which ensures a company to complete its various operational tasks, is the most effective of working methods and processes after a long-term accumulation and deposition. The information system includes the storage, disposal and transmission of the inner information of a company. A favorable information system enables a company to quicken the flow of the inner information, heighten the operational efficiency, and has ten learning within the company.

Table 2

The indices of Structural capital (Chen et al., 2004)

\begin{tabular}{|c|c|}
\hline Corporate culture & $\begin{array}{l}\text { Construction of company's culture } \\
\text { Employee's identification with company's } \\
\text { Perspective }\end{array}$ \\
\hline Organizational structure & $\begin{array}{l}\text { Clarification of relationship among authority, responsibility and benefit } \\
\text { Validity of enterprise controlling system }\end{array}$ \\
\hline Organizational learning & $\begin{array}{l}\text { Construction and utilization of inner information net } \\
\text { Construction and utilization of company } \\
\text { Repository }\end{array}$ \\
\hline Operation process & $\begin{array}{l}\text { Business process period } \\
\text { Product quality level } \\
\text { Corporate operating efficiency }\end{array}$ \\
\hline Information system & $\begin{array}{l}\text { Mutual support and cooperation among employees } \\
\text { Availability of enterprise information } \\
\text { Share of knowledge }\end{array}$ \\
\hline
\end{tabular}

\subsubsection{Relational capital}

Capital, an essential segment of IC, is the value embedded in the marketing sectors and relationships that an enterprise develops by conducting business. Compared with human capital and structural capital, it more directly influences the company value and is increasingly becoming the critical factor. In this study, customer capital is classified into basic marketing capability, market intensity and customer's loyalty (Table 3).

Market intensity, the ultimate expression of customer capital, refers to the current state of market building and it's potential. Customer loyalty is playing a more and more important role in today's heated competition (Chen et al., 2004). A company without loyal customers will have to resort to various sales promotions to allure new customers who are sometimes unprofitable to the company. Accordingly, the company should make great efforts to improve the quality of product and service pertaining to the current and future needs of customers, and to enhance customer satisfaction and thereupon customer loyalty (Chen et al., 2004). 
Table 3

The indices of relational capital (Chen et al., 2004)

\begin{tabular}{ll}
\hline \multirow{3}{*}{ Basic marketing capability } & $\begin{array}{l}\text { Construction and utilization of the customer database } \\
\text { Customer service capability } \\
\text { Identifying ability of customer's needs }\end{array}$ \\
& Market share \\
& Market potential \\
& Unit sales to customer \\
& Brand and trademark reputation \\
& Construction of sales channel \\
Customer loyalty & Customer satisfaction \\
& Customer complaint \\
& Customer outflow \\
Investment on customer relationship
\end{tabular}

\subsection{Knowledge creation}

To analyze the process of knowledge creation, it is necessary to use a categorization of knowledge, according to a relevant and generally accepted criterion. Thus, we take into account the renowned epistemological dimension of knowledge introduced by Polanyi (1966). This has become incredibly well-known because of the work of Nonaka and Takeuchi (1995), and has been extensively employed by theoretical and empirical literature (Kuang-Hsun et al., 2010).

The epistemological dimension distinguishes between tacit and explicit knowledge. Tacit knowledge is highly subjective, idiosyncratic and deeply rooted on personal experiences. On the contrary, articulated or explicit knowledge is objective and can be untied from the situation by which it was acquired. This knowledge is related to the rational, theoretical, and scientific activities in a positivistic sense. These characteristics make explicit knowledge easier to express and transmit than tacit knowledge.

Several authors such as Nonakaand Takeuchi (1997), Sanchez (2001), Asheim and Cohenen (2005) have tried to clarify how knowledge creation processes take place using the epistemological dimension, the ontological one, or both.

Kogut and Zander (1992) established the key for studying the role that knowledge plays in the firm. Although they do not mention in an explicit way, their model shows the relationship between the two perspectives that can be taken for analyzing knowledge. On one hand, we can see a static perspective, related to knowledge stocks or intellectual capital, when authors determine knowledge (information and know-how) in charge of firm sales in current markets, and knowledge, which can cause future market opportunities. On the other hand, we can see a dynamic analytic perspective, related to knowledge creation and organizational learning, when combinative capabilities of the firm are studied as ways to synthesize learning processes from inside or outside the firm (Nonaka \& Toyama,2007). We try to focus our study in this dynamic aspect.

\subsection{Knowledge creation dimensions}

The SECI (Socialization, Externalization, Combination, Internalization) model from Nonaka and Takeuchi (1995) performs a complete treatment about every combination of knowledge creation according to the tacit and explicit modes of knowledge.

- Socialization, from tacit to tacit knowledge;

- Externalization, from tacit to explicit knowledge;

- Combination, from explicit to explicit knowledge; and

- Internalization, from explicit to tacit knowledge (Table 4) (Nonaka, 1995). 
Table 4

Knowledge creation model

\section{From To}

Implicit knowledge

Explicit knowledge

\begin{tabular}{|l|l|l|}
\hline Implicit knowledge & $\begin{array}{l}\text { Socialization: process of } \\
\text { creating implicit knowledge } \\
\text { via experience sharing } \\
\text { (common knowledge) }\end{array}$ & $\begin{array}{l}\text { Externalization: implicit } \\
\text { knowledge } \\
\text { expressed with metaphors, } \\
\text { analogies, concepts, or } \\
\text { assumptions through models } \\
\text { (conceptual knowledge) }\end{array}$ \\
\hline Explicit knowledge & $\begin{array}{l}\text { Internalization: knowledge } \\
\text { passed downwith words and } \\
\text { stories or made intomanuals } \\
\text { and documents (operational } \\
\text { knowledge) }\end{array}$ & $\begin{array}{l}\text { Combination: the process of } \\
\text { forming aknowledge system } \\
\text { by making concepts } \\
\text { systematic } \\
\text { knowledge) }\end{array}$ \\
\hline
\end{tabular}

Source: Nonaka and Takeuchi (1995)

Now, describe dimensions of Knowledge Creation.

\subsubsection{Socialization}

At the organizational level, socialization or the creation of a shared body of tacit knowledge takes place through every social and cultural process linked to the ongoing organizational activities.

\subsubsection{Externalization}

Externalization is the procedure to change the implicit knowledge to explicit knowledge. For instance, a chief financial officer (CFO) of a company does not generate a conventional financial report, but rather, he introduces an innovative budgetary control method, which is based on implicit knowledge he has accumulated over years of experience.

\subsubsection{Combination}

This is an integration of all components to make the explicit knowledge systematic. For example, a $\mathrm{CFO}$ of a firm integrates information throughout the organization to compile it into a financial report, which is a new knowledge since it combines information of different sources.

\subsubsection{Internalization}

The aim of internalization is to change the explicit knowledge to implicit knowledge, via inspections and applications. The process socializes, externalizes, and combines the explicit languages, texts, pictures, or information, and then internalizes it into personal knowledge (Nonaka et al., 2000).

\section{Hypothesis development}

We suggest the following hypothesis based on the literature review to survey the relationship between intellectual capital and knowledge creation dimensions, 
Hypothesis 1. Human capital has meaningful effect on Internalization of knowledge.

Hypothesis 2. Human capital has meaningful effect on Externalization of knowledge.

Hypothesis 3. Human capital has meaningful effect on Combination of knowledge.

Hypothesis 4. Human capital has meaningful effect on Socialization of knowledge.

Hypothesis 5. structural capital has meaningful effect on Internalization of knowledge.

Hypothesis 6. structural capital has meaningful effect on Externalization of knowledge.

Hypothesis 7. structural capital has meaningful effect on Combination of knowledge.

Hypothesis 8. structural capital has meaningful effect on Socialization of knowledge.

Hypothesis 9. relational capital has meaningful effect on Internalization of knowledge.

Hypothesis 10. relational capital has meaningful effect on Externalization of knowledge.

Hypothesis 11. relational capital has meaningful effect on Combination of knowledge.

Hypothesis 12. relational capital has meaningful effect on Socialization of knowledge.

\section{Method}

\subsection{Data collection}

The population for the study consisted of the formal staffs (managers, senior staff and other staff) of the in the Headquarters of National Gas Corporation of Iran in the year 2010.We surveyed 350 employees who were working in this Corporation. Of 350 questionnaires, 270 questionnaires were returned. Among the respondents, 77.7 percent were male while 26.3 were female. Most respondents (54.8 percent) had a senior high school education, while 30.4 percent had a bachelor's degree, 14.8 percent junior high school and graduate degree. Finally the largest proportion of respondents (34.8 percent) were aged 31-35, followed by 26-30 (14.8percent), less than 25 (12.6 percent), 36-40 (11.9 percent), 46-50 (10.4 percent), 41-45 (9.6percent), and 51-55 (4.4 percent).

The research method is descriptive - survey and follows practical objective. We used structural equation modeling to test our conceptual models.

\subsection{Reliability and validity analyses}

The reliability of data collected was measured using Cranach's alpha coefficient. The reliability test was conducted to check for inter-item correlation in each of variables in the questionnaire. Cranach's alpha provides a good estimate of reliability and is preferred over split-half method. The notations of the variables shown in Table 5 are as follows: HC is Human Capital, SC is Structural Capital, RC is Relational Capital, E is Externalization, I is Internalization, $\mathrm{S}$ is Socialization and $\mathrm{C}$ is Combination. Table 5 shows the Cranach's alpha coefficient for all the variables in the questionnaire obtained. The value of at least 0.70 is the basis of reliability for Cranach's alpha coefficient. All responses collected had passed the reliability test.

\section{Table 5}

Summary of dimension reliability

\begin{tabular}{lll}
\hline variables & No. of items & Cranach's alpha coefficient \\
\hline HC & 9 & 0.8946 \\
SC & 10 & 0.8812 \\
RC & 8 & 0.9092 \\
I & 7 & 0.842 \\
E & 7 & 0.812 \\
S & 8 & 0.798 \\
C & 7 & 0.8721 \\
\hline
\end{tabular}


Meanwhile, content validity refers to the fitness of the contents of the measurement tool. The verification of content validity in social sciences depends on the professional knowledge of researchers. It is also possible to identify appropriate and relevant measurements from literature or employ the assistance of experts to determine the fitness of the contents, to enhance content validity, and ensure questionnaire effectiveness. The development of measurement tools in this paper is based on generalization of literature reviews. All the sources are referenced in relevant empirical literature. The questions are modified after interviews with experts. Therefore, the questionnaire in this paper should carry a certain degree of content validity.

In order to reach our goal to test empirically the SECI model, we developed a survey for the concepts that we wanted to analyze. Socialization was measured through six questions of frequency in a 1-5 Likert scale (never-always as pole extremes). Externalization, combination, and internalization were determined with five questions for each one (see Fig. 1). Also Human Capital was measured through six questions, Structural Capital (eight questions), and relational Capital was measured through seven questions. Every question was extracted from the theoretical or empirical literature (Nonaka et al., 2000; Egbu, 2006; Salisbury, 2001; smith, 2005). Although some items do not come directly from empirical works, they were adapted from examples and explanations of the main processes of the SECI (Nonaka \& Takeuchi, 1995). The following table shows the main inspiration of each of the questionnaire items for knowledge creation used in the survey. Further, some of the indices of Chen (2004) used for intellectual capital dimension.

Informal meetings like coffees, luncheons, and other social activities

Nonaka, Toyama, and Konno (2001)

Informal activities focused on free-time, and social activities outside the work place

Nonaka, Toyama, and Konno (2001)

Activities related to and master-apprentice relationships

Nonaka, Toyama, and Konno (2001); Salisbury, (2001)

Organizational members share beliefs, values, and ways of thinking

Nonaka, Toyama, and Konno (2001)

Expression of the corporate mission, vision, and values, as well as the organizational history through documents, policy declarations, etc.

Nonaka, Toyama, and Konno (2001); Schulz (2001)

Organizational routines are documented in schemes, organizational charts, flow charts, etc.

$\operatorname{smith}(2005)$

Utilization of metaphors, analogies and models to clarify concepts and ideas

Nonaka and Takeuchi(1995)

The information contained in files, databases, intranets, corporate networks, company software and other tools for information management is classified and accessed

Nonaka, Toyama, and Konno (2001)

We short, add, combine and classify already available information to develop written reports

Payne and Huffman(2003), Nonaka, Toyama, andKonno (2001)

The perspectives, insights, points of view, and mental models of the organization are shaped from data and information already available ,

Toyama, and Konno (2001);smith(2005)

Fig. 1. Questionnaire items for Knowledge Creation

\subsection{Structural equation modeling}

In order to examine goodness of the model, we used informative factor analysis and we used SEM by Lisrel to confirm or reject the hypothesis in this study. The indexes of goodness of the model are $\chi^{2}$, 
GFI, CFI. Thus, the model has goodness that $\chi^{2} / \mathrm{df}<3$ and GFI $>90 \%$, CFI $>90 \%$. The smaller RMSEA the better too.

Table 6 shows the averages and standard deviations of observed variables. Meanwhile, according to the skewness and slopes of individual variables, Kline (1998) made the following comments on coefficients of skewness and coefficients of kurtosis. He suggested that when the absolute value of the coefficient of the skewness of the distribution of variables is greater than three, it could be regarded as extremely skewed. If the absolute value of the coefficient of kurtosis is greater than eight, it has reached a critical point. If the coefficient of kurtosis is greater than 20 , it is seriously critical and can be regarded as an extreme case. If the coefficient of skewness or kurtosis has such an issue, it is necessary to consider the estimation methods not subject to the variable distribution.

The coefficients of skewness for the observed variables, in this paper, are from 20.484 to 0.327 , and the coefficients of kurtosis are from 20.354 to 2.032. The results show that an estimation method, with a normal distribution, does not seriously affect the robustness of the estimates. Therefore, this paper uses the maximum likelihood estimation method as its model.

Table 6

Measurements of observed variables for path analysis

\begin{tabular}{lllll}
\hline $\begin{array}{l}\text { Potential constructs } \\
\text { And observed variables }\end{array}$ & Average & $\begin{array}{l}\text { Standard } \\
\text { deviation }\end{array}$ & $\begin{array}{l}\text { Coefficient of } \\
\text { skewness }\end{array}$ & $\begin{array}{l}\text { Coefficient of } \\
\text { kurtosis }\end{array}$ \\
\hline Knowledge creation & & & & 2.032 \\
I & 4.06 & 0.48 & 0.484 & 0.063 \\
E & 3.60 & 0.55 & -0.063 & 0.224 \\
S & 3.79 & 0.48 & 0.243 & 0.064 \\
C & 3.92 & .51 & & 0.245 \\
Human capital & & & -0.074 & -0.354 \\
Employees' training & 3.33 & 0.68 & 0.226 & -0.310 \\
Employees' capabilities & 3.34 & 0.65 & -0.028 & -0.080 \\
Employees' satisfaction & 3.41 & 0.63 & & -0.008 \\
Structural capital & & & -0.102 & -0.121 \\
Treasury knowledge & 3.23 & 0.75 & -0.314 & 0.090 \\
Organizational culture & 3.39 & 0.69 & 0.087 & -0.066 \\
Innovation ability & 3.52 & 0.60 & & -0.191 \\
Relational capital & & & 0.312 & 0.327 \\
Customers' satisfaction & 3.57 & 0.57 & 0.099 & \\
Customers' loyalty & 3.39 & 0.61 & & \\
Market intensity & 3.49 & 0.59 & & \\
\hline
\end{tabular}

\section{Findings}

\subsection{Test of goodness of the conceptual model}

Conceptual model in this survey shows in framework structural equation model (SEM) and examine goodness of that with use several techniques.

In this study, the indexes of goodness show that model is fit goodness (Table7).

Table 7

The indexes of model goodness

\begin{tabular}{llll}
\hline Fit indicator & Validation value & Criteria & Result \\
\hline X2/df & 1.971 & $<3$ & Compliant \\
GFI & .93 & $>9$ & Compliant \\
CFI & .073 & $>9$ & Compliant \\
RMSEA & .94 & $<1$ & Compliant \\
\hline
\end{tabular}




\subsection{Response to Hypothesis}

In Fig. 2 and Table 8, we see meaningfully of coefficients and parameters get in structural model of the relationship between intellectual capital dimensions (human capital, structural capital, and relational capital) and knowledge creation dimensions (socialization, externalization, combination, internalization).

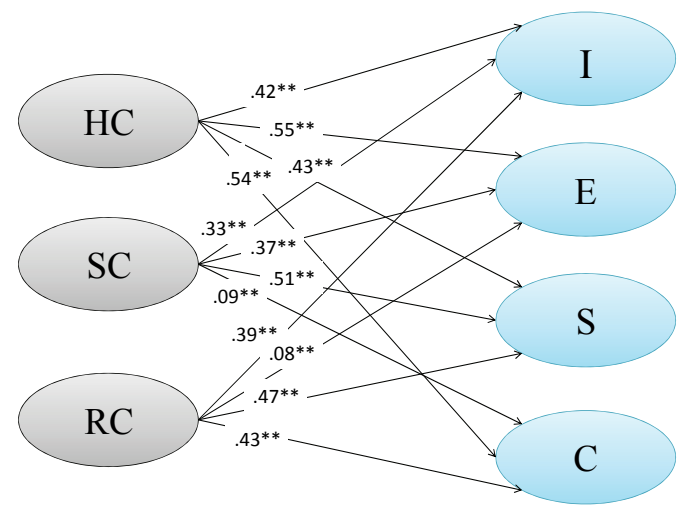

Fig. 2. Structural Equation Model in estimate state $\mathrm{p}<.01 * *$

Table 8

Findings of hypothesis test

\begin{tabular}{lllll}
\hline Hypothesis & $\mathrm{R} 2$ & $\mathrm{t}$-value & $\beta$ & result \\
\hline Hypothesis 1 & .42 & 4.42 & .36 & confirm \\
Hypothesis 2 & .55 & 5.02 & .43 & confirm \\
Hypothesis 3 & .43 & 4.44 & .34 & confirm \\
Hypothesis 4 & .54 & 5.47 & .46 & confirm \\
\hline Hypothesis 5 & .33 & 3.02 & .36 & confirm \\
Hypothesis 6 & .37 & 3.77 & .35 & confirm \\
Hypothesis 7 & .09 & 1.117 & .107 & reject \\
Hypothesis8 & .44 & 4.46 & .39 & confirm \\
Hypothesis9 & .39 & 3.57 & .32 & confirm \\
Hypothesis 10 & .08 & .842 & .57 & reject \\
Hypothesis 1 & .47 & 4.09 & .36 & confirm \\
Hypothesis 12 & .43 & 4.53 & .47 & confirm \\
\hline
\end{tabular}

\section{Conclusions and suggestions}

In this paper, we have examined the correlation between intellectual capital dimensions (human capital, structural capital, and relational capital) and knowledge creation dimensions (Socialization, Externalization, Combination, Internalization) of the Gas National Corporation Headquarter of Iran. The research finds that all dimensions of intellectual capital have a significant impact on dimensions of knowledge creation, except for the effects of structural capital on knowledge combination as well as relational capital on knowledge internalization. 
Therefore, knowledge creation in the Gas National Corporation Headquarter should focus on the exchange and sharing of information. It has suggested the usual approach adopted by Corporation is brain storming and workshops, and the connecting approach is team-oriented. Furthermore, the smoother the information communication channels are for employees to create knowledge, the higher the human capital of the corporate; as a result. In other words, with comprehensive knowledge creation mechanisms, corporate can effectively enhance their IC. This finding is consistent with that the most important activity in management of IC is the creation of knowledge variety. It can improve the flows of knowledge creation for an organization, and accumulate more knowledge assets. Meanwhile, as far as the sources of knowledge creation is concerned for employees in the this corporate, human capital are the most important and have the most significant influence on externalization $(0.55)$ and followed by relational capital on internalization reports the least influence on.

As far as the perception of the dimensions of IC by the employees in this corporate is concerned, this paper finds that employees' competences are the most important element of human capital, followed by employees' satisfaction and employees' training. When it comes to structural capital, innovation ability is the most important, followed by organizational culture and treasury value. In terms of customer capital, customers' loyalty is the most important, followed by customers' satisfaction and market shares. In other words, employees' competences, satisfaction, and training have positive influence on structural capital and customer capital. Customers' loyalty, satisfaction, and market shares also exhibit positive influence on structural capital.

The ability to create knowledge is highly relevant to IC. Companies should define their own robust mechanisms for knowledge creation to improve their ability in knowledge creation. The sources of knowledge creation should include human capital, structural capital, and relational capital. Thus the corporate should improve their mentoring systems in order to convert the implicit knowledge notable to be expressed with words or texts within the organization into explicit knowledge. Also should establish and integrate a variety of IT systems to facilitate the exchange and sharing of knowledge (Examples are databases, work samples, and instruction manuals within the organization). It is also possible to invite highly seasoned professionals to give speeches and encourage employees to sit for examinations to obtain certificates and qualifications. Finally, these should provide all kinds of formal, and informal, communication channels, such as job rotations, discussions, intranet forums, meeting rooms, and tea areas to enhance the ability of the organization to create knowledge.

The managers should identify the ways to cultivatein-depth contents of IC. They should have comprehensive talent development programs for their human capital by providing complete training and education to expand the professional knowledge and skills of employees. They should encourage employees in a timely manner to enhance employees' satisfaction. In terms of structural capital, the mangers should strive to improve the operational flows of their companies by enhancing the innovation capabilities and bettering the value of the knowledge treasury within their organizations. Also the managers should identify the ways to cultivate in-depth contents of IC. They should have comprehensive talent development programs for their human capital by providing complete training and education to expand the professional knowledge and skills of employees. They should encourage employees in a timely manner to enhance employees' satisfaction. In terms of structural capital, the mangers should strive to improve the operational flows of their companies by enhancing the innovation capabilities and bettering the value of the knowledge treasury within their organizations.

Liew (2008) suggested the integration of KM and CRM is a strategic issue that has strong ramifications in the long-term competitiveness of organizations. This will increase customers' satisfaction and loyalty, and hence, market shares. For domestic corporate, the interaction and mutual influence of human capital, structural capital, and customer capital will benefit the accumulation of IC, create differentiated advantages, and boost corporate competitiveness. 


\section{Acknowledgment}

The authors would like to thank the anonymous referees for constructive comments on earlier version of this work.

\section{References}

Al-Ali, N. (2003). Comprehensive Intellectual Capital Management, Wiley, Hoboken, NJ.

Bontis, N. (2004). National intellectual capital index: a United Nations initiative for the Arab region. Journal of Intellectual Capital, 5(1), 13-39.

Chen, J., Zhu, Z., \& Xie, H.Y. (2004). Measuring intellectual capital: a new model and empirical study. Journal of Intellectual Capital, 5()1,192-212.

Chong, S.C., \& Lin, B. (2008). Exploring knowledge management issues and KM performance outcomes: empirical evidence from Malaysian multimedia super corridor companies. International Journal of Technology Management, 43(4), 285-303.

Cuganesan, S. (2005). Intellectual capital-in-action and value creation: a case study of knowledge transformations in an innovation project. Journal of Intellectual Capital, 6(3), 357-73.

Dzinkowski, R. (2000). The measurement and management of intellectual capital: an introduction. Management Accounting, 78(2), 32-36.

Guthrie, J. (2001). The management, measurement and reporting of intellectual capital. Journal of Intellectual Capital, 2(1), 27-41.

Ho, C.T. (2009). The relationship between knowledge management enablers and performance. Industrial Management \& Data Systems, 109(1), 98-117.

Huang, F. (2004). Social Science Statistics - Structural Equation Modeling. WuNan, Taipei.

Joia, L.A. (2000). Measuring intangible corporate assets. Journal of Intellectual Capital, 1(1), 68-84.

Kuang-Hsun, S., Chia-Jung, C.\& Binshan, L.(2010) Assessing knowledge creation and intellectual capital in banking industry. Journal of Intellectual Capital, 11(1), 74-89.

Liew, C.A.A. (2008). Strategic integration of knowledge management and customer relationship management. Journal of Knowledge Management, 12(4), 131-146.

Mason, E. (2006). Are you missing your firm's intellectual capital. Accounting Today, May, 8-9.

Mayo, A. (2001). The Human Value of the Enterprise: Valuing People as Assets Monitoring. Nicholas Brealey, London.

McElroy, M.W. (2002). Social innovation capital. Journal of Intellectual Capital, 3(1), 30-39.

Nonaka, I., \& Takeuchi, H. (1995). The Knowledge Creating Company. Oxford University Press, New York, NY.

Nonaka, I., \& Toyama, R. (2007). Why do firms differ? The theory of the knowledge creating firm. 5(1), 14-37.

Petty, R., Ricceri, F., \& Guthrie, J. (2008). Intellectual capital: a user's perspective. Management Research News, 31(6), 437-447.

Phusavat, K., \& Kanchana, R. (2007). Competitive priorities of manufacturing firms in Thailand. Industrial Management \& Data Systems, 107(7), 979-996.

Rastogi, N.P. (2000). Knowledge management and intellectual capital: the new virtuous reality of competitiveness. Human Systems Management, 19, 39-48.

Rezgui, Y. (2007). Knowledge systems and value creation: an action research investigation. Industrial Management \& Data Systems, 107(2), 166-182.

Salisbury, M. (2001). An example of managing the knowledge creation process for a small work group. Management Learning, 32(4), 305-319.

Schiuma, G., \& Lerro, A. (2008). Intellectual capital and company's performance improvement. Measuring Business Excellence, 12(2), 3-14. 
Smith, K. G., Collins, C. J., \& Clark, K. D. (2005). Existing knowledge, knowledge creation capability, and the rate of new product introduction in high-technology firms. Academy of Management Journal, 48(2), 346-357.

Walsh, K., Enz, A.C., \& Canina, L. (2008), The impact of strategic orientation on intellectual capital investments in customer service firms. Journal of Service Research, 10(4), 300-317.

Wu, A. (2002). Assessing intellectual capital. Accounting Research Monthly, 204, 57-66. 